\title{
Behavior, growth, and survivorship of laboratory-reared juvenile gopher tortoises following hard release
}

\author{
Thomas A. Radzio ${ }^{1, *}$, Nicholas J. Blase ${ }^{1}$, James A. Cox ${ }^{2}$, David K. Delaney ${ }^{3}$, \\ Michael P. O'Connor ${ }^{1}$
}

\begin{abstract}
${ }^{1}$ Department of Biodiversity, Earth, and Environmental Science, Drexel University, Philadelphia, Pennsylvania 19104, USA
${ }^{2}$ Tall Timbers Research Station and Land Conservancy, Tallahassee, Florida 32312, USA

${ }^{3}$ United States Army Construction Engineering Research Laboratory, Champaign, Illinois 61822, USA
\end{abstract}

\begin{abstract}
Captive rearing represents a vital component of many conservation and research programs. However, captive animals can exhibit unnatural behaviors and experience high predation following release, which can limit reintroduction success and the inferential value of studies that use released animals. Soft-release measures (e.g. penning) can acclimate individuals and limit interactions with predators but can also require considerable resources. We reared hatchling gopher tortoises Gopherus polyphemus in the laboratory for physiology experiments and subsequently hard-released them as yearlings to assess the efficacy of this low-cost release method and to explore possible captivity effects on tortoise behavior, growth, and survivorship. Hard-released yearlings exhibited limited dispersal; most constructed burrows soon after release, and, like wild juveniles, exhibited a preference for burrowing under deadwood. Video observations at burrows indicated natural behavior, including overnighting in burrows, extensive basking directly in front of burrows, and limited time away from these important refugia. Basking tortoises responded to simulated predator approach by rapidly entering burrows, with flight initiation distances and hiding times equivalent or similar to those of wild individuals. Survivorship was comparable to that of soft-released juveniles, but growth was slightly lower than expected based on observations of wild tortoises at the site, possibly reflecting performance immediately following release. Our findings indicate that captive-reared juvenile gopher tortoises respond well to hard release and exhibit natural attributes required to thrive in the wild. Moreover, studies of released juveniles can yield valuable insights into the ecology of a life stage that is poorly understood in most chelonians.
\end{abstract}

KEY WORDS: Gopherus polyphemus - Turtle - Conservation - Headstarting - Antipredator behavior · Thermal ecology

\section{INTRODUCTION}

Maintaining animals in captivity represents a vital component of many conservation and research programs (Swimmer et al. 2005, Crone et al. 2007, Griffiths \& Pavajeau 2008). However, reintroducing captive animals into the wild can present challenges,

*Corresponding author: tomradzio@hotmail.com

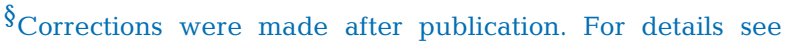
www.int-res.com/abstracts/esr/v40/c_p17-29/

This corrected version: October 8, 2019 often because released individuals experience high predator-induced mortality (Moseby et al. 2011, Holbrook et al. 2015, Tuberville et al. 2015). Released animals can be more vulnerable to predators than their wild counterparts for a number of reasons, including lack of familiarity with their surroundings, limited access to refugia, and unnatural behaviors

(C) The authors 2019. Open Access under Creative Commons by Attribution Licence. Use, distribution and reproduction are unrestricted. Authors and original publication must be credited.

Publisher: Inter-Research · www.int-res.com 
(Beck et al. 1994, Tuberville et al. 2015). Measures to improve reintroduction success include captive conditions that promote natural behavior and release protocols that reduce interactions with predators (Biggins et al. 1998, Stamps \& Swaisgood 2007, Reading et al. 2013, Tuberville et al. 2015).

Chelonians are declining worldwide owing to a variety of threats (Buhlmann et al. 2009, Böhm et al. 2013, Lovich et al. 2018), and for some critically endangered species, captive breeding may represent a necessary action to reestablish viable wild populations (Milinkovitch et al. 2013, Spencer et al. 2017). This approach can work, but success may require decades of repeated effort (Milinkovitch et al. 2013), in part due to life history traits such as low survival of small juveniles and delayed sexual maturity (Congdon \& Gibbons 1990, Heppell et al. 1996). Therefore, long-term evaluations may be needed to truly understand the effectiveness of such programs (Dodd \& Seigel 1991, Milinkovitch et al. 2013). However, short-term studies of behavior, growth, and survivorship can provide important information for intermediate assessment and calibration of release efforts (Pedrono \& Sarovy 2000, Lepeigneul et al. 2014, Tuberville et al. 2015, Spencer et al. 2017).

Development of effective release protocols and knowledge of captivity effects on behavior may not only improve reintroduction success but can also advance other conservation-oriented objectives. For example, released juveniles can provide convenient opportunities to study the ecology, including habitat requirements, of a life stage that is poorly understood in most chelonians (e.g. Mansfield et al. 2014, Nagy et al. 2015, Todd et al. 2016, Nafus et al. 2017). However, such studies often depend on the assumption that behavior does not differ materially between released and wild individuals. Establishment of costefficient, but effective, release protocols could also ease financial barriers associated with conducting important laboratory research on sensitive species that must be responsibly released at the conclusion of experiments (Holbrook et al. 2015, Quinn 2016, Radzio 2017).

The gopher tortoise Gopherus polyphemus is a threatened herbivore of the southeastern USA (McCoy et al. 2006, Smith et al. 2006, USFWS et al. 2013) that relies on self-constructed burrows for predator avoidance and thermoregulation (Douglass \& Layne 1978, Wilson et al. 1994, Pike \& Grosse 2006, Radzio \& O'Connor 2017). In addition to conserving and restoring semi-open upland habitats, such as longleaf pine Pinus palustris savannas (Diemer 1986, Smith et al. 2006, USFWS et al. 2013), biologists across multiple states (Mississippi, Georgia, South Carolina, Florida) are investigating the management value of head-starting, a process whereby hatchlings are reared in captivity and released after having grown to larger sizes at which they are presumably less vulnerable to predators (Tuberville et al. 2015, Quinn et al. 2018). Release methods for juvenile gopher tortoises, either animals raised in captivity for head-starting or laboratory research, include 'soft release,' where individuals are provided starter burrows and/or penned to limit movements and interactions with predators, or 'hard release,' where tortoises are simply released without additional measures (Holbrook et al. 2015, Tuberville et al. 2015, Quinn et al. 2018). Hard release requires minimal resources and could facilitate novel ecological research, but its efficacy remains unclear with gopher tortoises. In a preliminary study, Quinn (2016) hard-released 10 captive-reared yearling gopher tortoises and found that 8 survived at least 2 mo, a promising result, as small wild juveniles experience intense predation pressure (Wilson 1991), and mortality can be high following soft release (Holbrook et al. 2015, Tuberville et al. 2015, Quinn et al. 2018).

We reared hatchling gopher tortoises in the laboratory for physiology experiments (Radzio 2017) and later hard-released them as yearlings. Given low annual survival of small juveniles (0.45, Wilson 1991), we expected few hard-released yearlings to survive over the long term. However, we used this as an opportunity to investigate the efficacy of hard release as a low-cost release approach that can aid tortoise conservation and research. We assessed post-release burrowing behavior, activity patterns, antipredator responses, growth, and survivorship and, when possible, evaluated these parameters with respect to available values for soft-released and wild juvenile gopher tortoises. By including behavioral assessments, we hoped to glean mechanistic insights into the relative performance of hard-released individuals, their suitability for ecological studies, and the ecology of juvenile gopher tortoises overall.

\section{MATERIALS AND METHODS}

\subsection{Study species}

The gopher tortoise is an herbivore of the southeastern USA that primarily inhabits well-drained upland habitats with semi-open to open canopies (Diemer 1986, Smith et al. 2006, USFWS et al. 2013). Juveniles and adults construct burrows, which they 
rely on for thermoregulation and predator avoidance (Douglass \& Layne 1978, Wilson et al. 1994, Pike \& Grosse 2006). Small juveniles center daily activities on burrows and have small home ranges (typically $<0.5$ ha; Wilson et al. 1994, Butler et al. 1995, Pike \& Grosse 2006). At our Georgia study site (described in Section 2.2), juveniles bask extensively on burrow aprons (bare soil directly in front of burrows), but quickly hide belowground in response to researcher approach (Radzio 2017, Radzio \& O'Connor 2017). Small juveniles from Georgia populations grow on average $12-19 \mathrm{~mm} \mathrm{yr}^{-1}$, and individuals may require 8-21 yr to mature, depending on sex and location (Landers et al. 1982, Harris 2014). Although highly variable, growth rates may be very important because small juveniles experience intense predation pressure and exhibit low annual survival (0.45, Wilson 1991).

\subsection{Study site}

We conducted this study on Arcadia Plantation $\left(30^{\circ} 45^{\prime} \mathrm{N}, 84^{\circ} 0^{\prime} \mathrm{W}\right)$, a 957 ha private property in southwest Georgia, USA. The site consisted primarily of mature and old-growth longleaf pine forest with ground cover composed predominantly of wiregrass Aristida stricta, oak (Quercus spp.), and other native plants (Platt et al. 1988). Soils were a complex mosaic of sand and clay. The site has been managed using frequent prescribed fire ( $\leq 2 \mathrm{yr}$ return interval), often implemented during the growing season, and supports a large gopher tortoise population (Tuberville et al. 2014).

\subsection{Study animals}

We collected hatchlings in September-October 2013 as they emerged from natural nests (Radzio et al. 2017). Individuals were uniquely marked (Cagle 1939) and reared indoors for thermal physiology studies under conditions that varied with experimental requirements (Radzio 2017). In general, hatchlings were housed in plastic enclosures $(53 \times 9$ and $29 \times 16 \mathrm{~cm})$ containing an artificial burrow and experienced a 13:11 h light:dark cycle, with more-limited exposure to artificial UVB radiation (160-W Powersun UV mercury vapor and 15-W T8 ReptiSun UVB 5.0 bulbs, Zoo Med Laboratories). Hatchling body temperatures generally ranged between 24 and $36^{\circ} \mathrm{C}$. Individuals were soaked in a water container every 1-4 d and fed primarily organic chicory (Chicorium spp., locally sourced), Oxbow Orchard Grass Hay (Oxbow Animal Health), and Natural Grassland Tortoise Food (Zoo Med Laboratories), occasionally supplemented with calcium (Repti Calcium, Zoo Med Laboratories) and vitamins (Herptivite, Rep-Cal Research Labs).

\subsection{Hard releases}

We fitted 30 individuals with miniature radio transmitters (model BD-2, Holohil; or model R1655, Advanced Telemetry Systems) and iButton temperature data loggers (Maxim Integrated Products) programmed to record temperature at 10 or 30 min intervals. To minimize impacts on tortoise movements, transmitters were customized with highly flexible trailing antennas (thin with no rubber tubing at bases). Prior to attachment, transmitters and iButtons were coated in brown rubber (Plasti Dip International). We epoxied transmitters to the posterior-most left or right costal scute and iButtons to the posteriormost vertebral scute. To avoid adversely affecting shell growth, we did not attach equipment to multiple scutes. Equipment and epoxy weighed approximately $5 \mathrm{~g}$, or $5-9 \%$ of tortoise mass. Time-lapse video observations of naturally occurring overturning events in this and other studies at the site indicated that iButtons and radio transmitters did not prevent individuals from righting (Radzio et al. 2016, Radzio 2017).

On the afternoon of 1 September 2014, we released 30 radio-transmittered yearlings from 15 clutches at or near their nest sites. If the nest site was at an active adult tortoise burrow, we released yearlings several meters away to limit potential interactions with large individuals. We also found many ants at the nest site of 1 yearling and released that individual near another yearling's nest site in the same area. A weather station at the site indicated that conditions during the following $24 \mathrm{~h}$ included air temperatures (at $1.5 \mathrm{~m}$ ) as high as $37.6^{\circ} \mathrm{C}$ coupled with full solar radiation $\left(984 \mathrm{~W} \mathrm{~m}^{-2}\right.$ ). On 22 September 2014, we released 28 additional yearlings from 14 clutches at or near their nest sites without radio transmitters or iButtons. In total, we released 58 tortoises (mean \pm SD midline plastron length $[\mathrm{MPL}]=63.3 \pm 3.5 \mathrm{~mm}$, range: 55.9-69.1 mm), 1-5 from each of 16 clutches, at 15 release points distributed widely across the study site. We measured MPL rather than midline carapace length (MCL) because iButtons affixed to rear vertebral scutes precluded accurate MCL measurements. However, by using the equation: $\mathrm{MCL}=$ 
MPL $\times 0.90+9.79$, derived from June 2014 laboratory measurements of the same individuals $\left(\mathrm{r}^{2}=0.68\right)$, we estimated MCL at release to have been $66.8 \pm 3.1 \mathrm{~mm}$ (60.2-72.1 mm).

\subsection{Burrowing and dispersal}

We tracked radio-transmittered tortoises every 2-6 d for 1 mo (2 September-1 October 2014). When we located a tortoise, we recorded whether it was in a burrow, on a burrow apron, or at the surface away from a burrow apron. For burrows constructed by radio-transmittered tortoises, we determined distance to release location using a measuring tape.

We also investigated whether, like wild juveniles (Aresco 1999), individuals released with transmitters disproportionately dug burrow entrances under deadwood (sticks, logs, bark, or pinecones $>2 \mathrm{~cm}$ in diameter) by determining presence/absence of deadwood at burrows and nearby random points. We located 3 random points at each burrow by extending a measuring tape in a random compass direction and distance, ranging from 1-11 $\mathrm{m}$, from each burrow. We considered points to coincide with deadwood if deadwood was present within $10 \mathrm{~cm}$. In one instance, a random point corresponded to an adult tortoise burrow apron and, in another, a sheer slope next to a dirt road. We generated new random points in both instances because these were locations where juveniles are unlikely to burrow.

\subsection{Activity, microhabitat use, and temperature relations}

We quantified activity, microhabitat use, and temperature relations of released tortoises. Between 30 September and 3 October 2014, video cameras and temperature data loggers recorded 1 complete daylight period for 19 of 20 transmittered yearlings observed alive and using a long burrow. Prior to observation days, we mounted time-lapse video cameras (Plotwatcher Pro, Day 6 Outdoors) on wooden poles next to burrows and trained them on burrow entrances, aprons, and nearby surrounding areas. We programmed cameras to continuously record $(0.33$ frames $\mathrm{s}^{-1}$ ) during daylight hours. To avoid influencing tortoise behavior, we did not visit burrows during recordings. A metal model (Radzio \& O'Connor 2017) recorded operative temperatures on each videorecorded tortoise's burrow apron at 10 min intervals. Similarly, iButtons attached to flexible tubing re- corded temperatures at different distances $(10,60$, 110 , and $160 \mathrm{~cm}$ ) inside 4 small, wild juvenile burrows at 10 min intervals.

\subsection{Antipredator flight response and hiding time}

We assessed responses of individuals on burrow aprons to simulated predator approach (Radzio \& O'Connor 2017). Between 10 September and 10 October 2014, a single researcher performed simulated predator approaches on 23 of 24 transmittered yearlings observed to be alive and using a long burrow. Wild juvenile gopher tortoises hide in response to researcher approach and exhibit long flight initiation distances (FIDs), making them difficult or impossible to observe visually (Radzio \& O'Connor 2017). Therefore, we used time-lapse video cameras, set prior to approach days, to document tortoise responses.

The researcher typically approached burrows by walking $\left(\sim 1.5 \mathrm{~m} \mathrm{~s}^{-1}\right)$ a straight path, starting $\geq 60 \mathrm{~m}$ away. For logistical reasons, in a small number of instances, the researcher approached a burrow, then immediately approached a second burrow located nearby, thus starting the second approach from a shorter distance. These short approaches were not used to estimate FIDs, but they were used to determine if individuals hid and for how long. When the researcher arrived at a burrow, he briefly placed his hand in front of the camera to record the exact time, which was used to estimate FID (described in Section 2.9). The researcher then immediately left the area, allowing the tortoise to emerge undisturbed. Burrows were approached only once a day, but this protocol was repeated on multiple days to ensure that each tortoise was approached at least once while basking on its burrow apron. Many basking individuals were approached multiple times.

\subsection{Growth and survivorship}

To assess growth, we measured MPL and mass at release in September 2014 and during subsequent captures through May 2016. To assess short-term survivorship, we followed tortoises fitted with radio transmitters $(\mathrm{n}=30)$ from 1 September 2014 to 1 April 2015. Starting in early October 2014, we captured individuals, primarily as they foraged away from burrows, to remove their transmitters. However, because tortoises generally use the same burrows between fall and spring, we were able to follow 19 of 22 transmittered individuals observed alive in early October 
2014 through early April 2015. To assess long-term minimum survivorship (i.e. return rates), we visually searched for all tortoises released in September 2014 $(\mathrm{n}=58)$, minus known depredated individuals, through August 2016. We did not physically capture tortoises in August 2016, but instead used video observations of scute notches to identify individuals.

\subsection{Statistical analysis}

We assessed time to burrow initiation and distance from release sites to burrows for radio-transmittered tortoises. We also tested for associations between burrows and deadwood (Aresco 1999) for transmittered tortoises, first using burrows and then individual tortoises as the unit of analysis. To investigate potential associations at the burrow level, we analyzed observed and expected frequencies of deadwood at burrows and random points using a chisquared goodness-of-fit test. To investigate potential associations at the individual level, we analyzed log odds ratios of deadwood occurrence at burrows and random points. We bootstrapped observations to account for tortoises that constructed multiple burrows. For each iteration, we selected a tortoise at random and calculated a log odds ratio for its burrow and its associated random points. If the tortoise had more than 1 burrow, we selected a burrow at random. The p-value was the proportion of iterations $\left(10^{6}\right)$ where the log odds ratio was $\leq 0$.

We compared activity, microhabitat use, and temperature relations of individuals fitted with transmitters to available accounts of wild juveniles (Wilson et al. 1994, Pike \& Grosse 2006, Radzio 2017, Radzio \& O'Connor 2017). We limited our analysis to qualitative comparisons because juvenile gopher tortoise activity varies with temperature (Radzio \& O'Connor 2017 ), and possibly other variables, in ways that remain incompletely understood. As a general rule, wild juveniles occupy burrows at night and spend limited time away from these refugia during the day (Wilson et al. 1994, Pike \& Grosse 2006, Radzio \& O'Connor 2017). Small juveniles at our study site do, however, bask extensively on burrow aprons, which raises their body temperatures above those typically found belowground (Radzio 2017, Radzio \& O'Connor 2017).

We estimated FID as the product of approach speed $\left(1.5 \mathrm{~m} \mathrm{~s}^{-1}\right)$ and number of seconds between when an approached tortoise initiated flight response and when the approaching researcher arrived at the burrow (Radzio \& O'Connor 2017). When an individual was approached more than once, we calculated a mean FID and hiding time value for the tortoise. We compared mean FID of released yearlings to that of $12 \mathrm{mo}$ old wild individuals at the site $(31.5 \mathrm{~m}$, extrapolated from Radzio \& O'Connor 2017) using a 1-sample $t$-test. We defined hiding time as the period from when an individual hid in its burrow until any portion of the tortoise reappeared outside. We compared hiding times of released yearlings to those of $0.5-4.0 \mathrm{yr}$ old wild tortoises (Radzio \& O'Connor 2017) using a Mann-Whitney $U$-test.

We quantified change in MPL and mass at 1-2 and 19-20 mo following release. We compared change in MPL at 19-20 mo following release to the predicted growth of wild juveniles at the study site. We calculated predicted growth for wild juveniles as the product of MPL growth rate of wild juvenile (age 1-4 yr) tortoises at the site $\left(15.6 \mathrm{~mm} \mathrm{yr}^{-1}, 95 \% \mathrm{CI}: 13.4-\right.$ $17.9 \mathrm{~mm} \mathrm{yr}^{-1}$; Fig. A1 in the Appendix) and number of growing years occurring between release and final capture. Growing years were calculated to account for seasonal tortoise growth in southwest Georgia, where $0 \%$ of annual growth occurs in JanuaryFebruary, 5\% in March-April, $34 \%$ in May-June, $34 \%$ in July-August, $17 \%$ in September-October, and $7 \%$ in November-December (Landers et al. $1982)$; in order for values to sum to $100 \%$, we added $0.5 \%$ to each bimonthly period. Thus, a tortoise released on 1 September 2014 and recaptured on 1 May 2016 would have experienced 1.66 actual years between measurements, but only 1.31 growing years and have a predicted growth value of $20.4 \mathrm{~mm}(95 \%$ prediction interval: $17.5-23.4 \mathrm{~mm}$ ).

Likelihood of location on or after 1 August 2016 was analyzed by a generalized linear mixed model with MPL at release and release date (1 or 22 September 2014) as fixed effects and clutch as a random effect ('Ime4' package in the program R, Bates et al. 2015). Location success was binary; individuals were either located or not. Statistical tests were 2-tailed, evaluated at alpha $=0.05$, and performed in SPSS (version 24.0, IBM Corp. 2015), R (version 3.4.4, R Core Team 2018), or MATLAB (version 9.5.0.944444 R2018b, MATLAB 2018).

\section{RESULTS}

\subsection{Burrowing and dispersal}

At least 14 of $30(\geq 47 \%)$ radio-transmittered tortoises started constructing a burrow within $2 \mathrm{~d}$ of hard release $_{i} \geq 22(\geq 73 \%)$ initiated a burrow within $4 d_{\text {; }}$ 
and $\geq 27$ ( $\geq 90 \%$ ) had done so within 13 d (Fig. 1). A $28^{\text {th }}$ tortoise was observed burrowing $21 \mathrm{~d}$ after release. The 2 tortoises not known to initiate burrows were found dead, apparently depredated, 4 and $6 \mathrm{~d}$ following release. In total, we documented 36 burrowing attempts (1-3 ind. ${ }^{-1}$ ) by 28 radio-transmittered yearlings during the first month following hard release. At least 2 individuals also briefly used an adult or wild juvenile burrow before burrowing. On average, burrows constructed during the first month were located $29.4 \pm 29.9 \mathrm{~m}(\mathrm{SD})($ median $=20.6 \mathrm{~m}$, range $=3.0-135.2 \mathrm{~m}$ ) away from release sites. Most (31 of $36,86 \%$ ) were $<50 \mathrm{~m}$ away. Surface-active tortoises were found within $\sim 20 \mathrm{~m}$ of their burrows. No tortoise, including depredated individuals, was observed more than $170 \mathrm{~m}$ from its release site at any point in the nearly 2 yr study.

Burrows initiated by transmittered tortoises during the month following release were positively associated with deadwood $\left(\chi^{2}=19.8, p<0.00001\right)$. Fifteen of 36 $(42 \%)$ burrow entrances were constructed under deadwood, while only 10 of 108 (9\%) random points fell within $10 \mathrm{~cm}$ of deadwood. Qualitatively, deadwood at burrows tended to be larger than deadwood at random points, suggesting that our analysis was conservative. In addition, 3 transmittered tortoises constructed burrows in stumpholes (holes left by dead trees and not classified as deadwood in our analyses). Analysis at the individual tortoise level revealed that individuals positively selected deadwood as burrowing microhabitat ( $\mathrm{p}=0.0012$ using bootstrapped log odds ratios).

We located 11 of 58 (19\%) tortoises in early August 2016, nearly 2 yr following hard release. These indi-

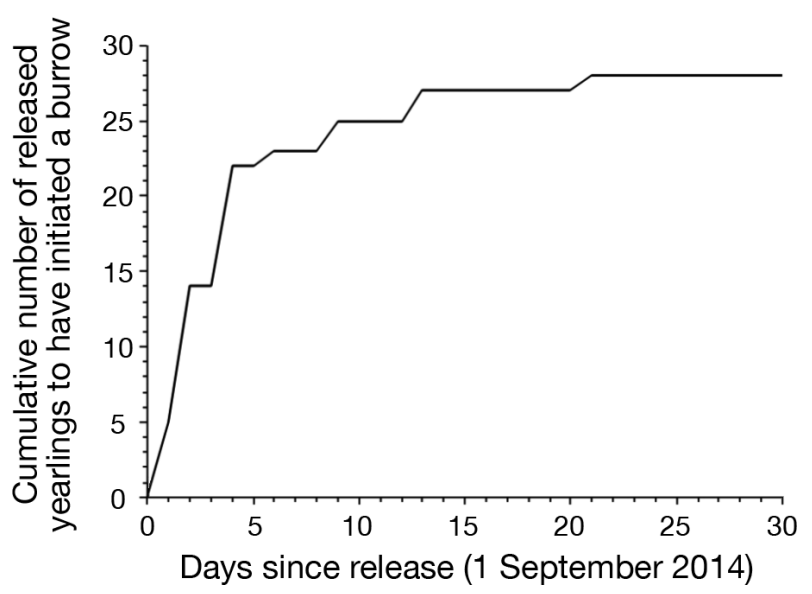

Fig. 1. Cumulative number of laboratory-reared, yearling gopher tortoises (out of 30) that initiated a burrow as a function of days since hard release in a longleaf pine forest in southwest Georgia, USA. The 2 tortoises that did not burrow were both apparently depredated within $6 \mathrm{~d}$ of release viduals were using burrows located $29.9 \pm 36.7 \mathrm{~m}$ from release sites $($ median $=16.6 \mathrm{~m}$, range $=3.0-135.2 \mathrm{~m}$ ). Distances are close approximations, as measurements were made from nest sites, but some yearlings were released several meters away from nest sites. We located a $12^{\text {th }}$ surviving individual in May 2019, approximately $120 \mathrm{~m}$ from its release site.

\subsection{Activity, microhabitat use, and temperature relations}

During 30 September-3 October 2014 video observations, tortoises $(n=19)$ emerged from burrows between $07: 30$ and 10:00 $\mathrm{h}$ and spent on average 7.6 $\pm 1.3 \mathrm{~h}(4.8-10.0 \mathrm{~h})$ at the surface, of which $6.4 \pm 1.7 \mathrm{~h}$ $(2.0-9.8 \mathrm{~h})$ were in burrow entrances or on burrow aprons and $1.2 \pm 1.8 \mathrm{~h}(0.0-8.0 \mathrm{~h})$ were away from burrow areas (Fig. 2). One yearling left its burrow apron around 10:30 $\mathrm{h}$ and did not return until the following day. The iButton temperature profile for this individual indicated that it probably spent the night aboveground. All other tortoises returned to their burrows by 15:40 h. By dusk (when the cameras turned off), 14 tortoises were fully inside their burrows, but 4 were only partially inside burrow entrances (Fig. 2). Additional observations, made soon after release and during simulated predator approaches, indicated similar activity.

Temperatures 60-160 cm inside burrows remained constant at $25^{\circ} \mathrm{C}$ throughout the diel cycle, but temperatures $10 \mathrm{~cm}$ from the surface fluctuated considerably. Surface operative temperatures typically exceeded burrow temperatures from midmorning to late afternoon (Fig. 3). By using burrow entrances and aprons, tortoises elevated shell temperatures above those available belowground (Fig. 3).

\subsection{Apparent burrow defense behavior}

On 2 September 2014, we placed a coaxial cable attached to a radio telemetry receiver inside a newly dug burrow to confirm presence of the yearling. The yearling repeatedly rammed the BNC connector of the coaxial cable with its gular protrusion and continued this behavior as we slowly retracted the cable. In early October 2014, we wanted to capture this tortoise to remove its iButton (its transmitter had detached prematurely) and obtain growth measurements. We placed a dowel into its burrow and moved it around in front of the tortoise and lightly touched the tortoise. The juvenile vigorously 


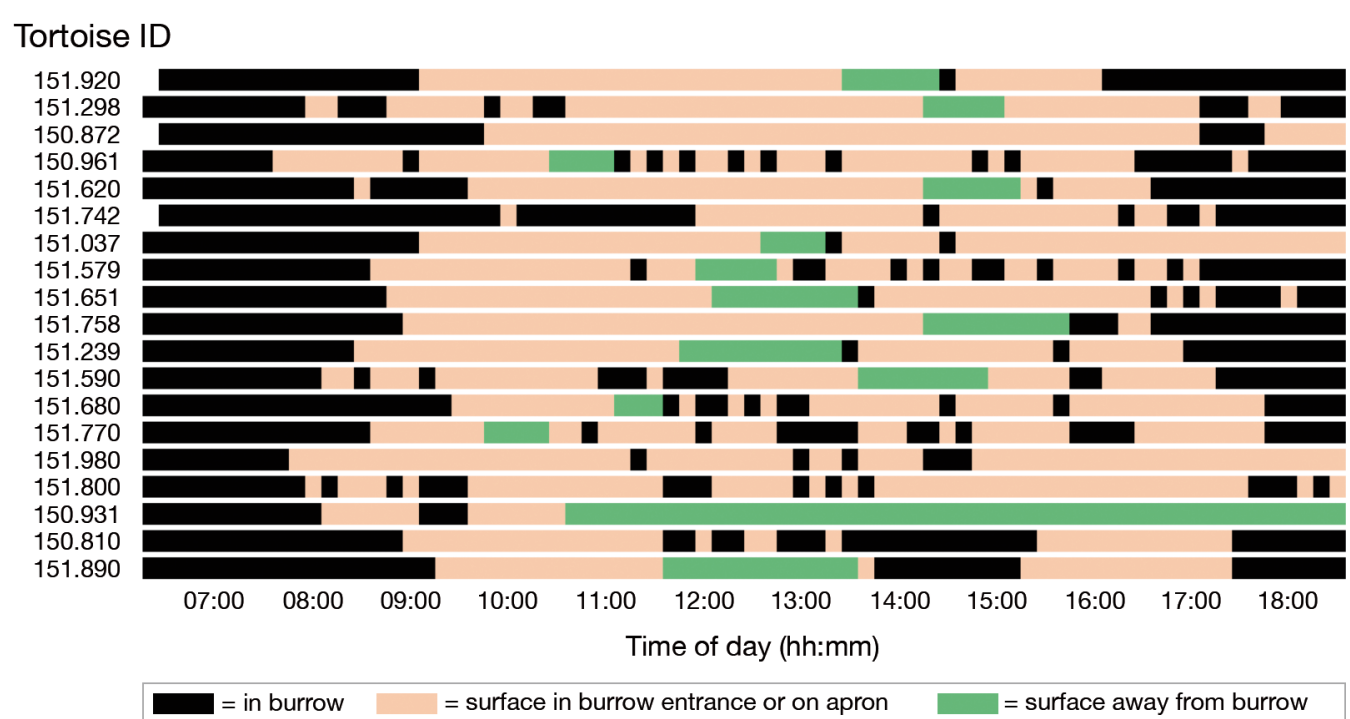

Fig. 2. Diurnal activity and microhabitat use patterns of 19 laboratory-reared, yearling gopher tortoises approximately 1 mo following hard release in a longleaf pine forest in southwest Georgia, USA. Each horizontal bar depicts microhabitat use for 1 individual video-recorded during 1 diurnal period between 30 September and 3 October 2014. Microhabitat use was manually point-sampled from video observations at $10 \mathrm{~min}$ intervals and extrapolated. Additional video recordings made during simulated predator approaches indicated similar activity patterns

(a) Cool days

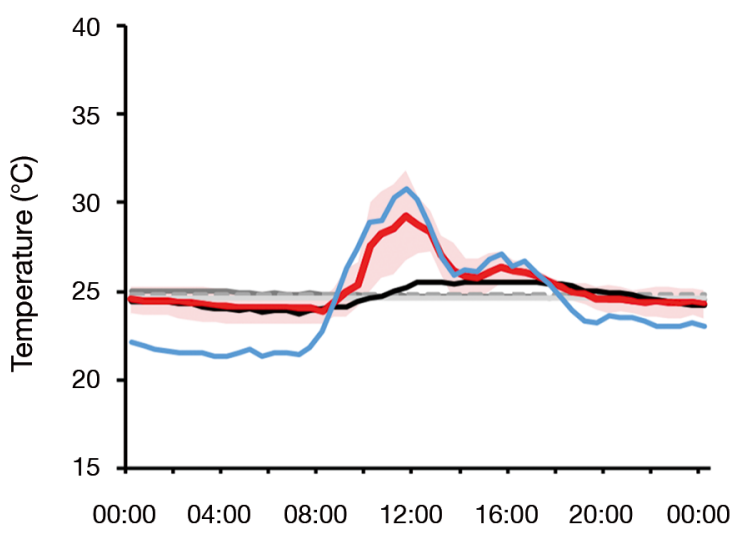

Time of day (hh:mm) (b) Warm days

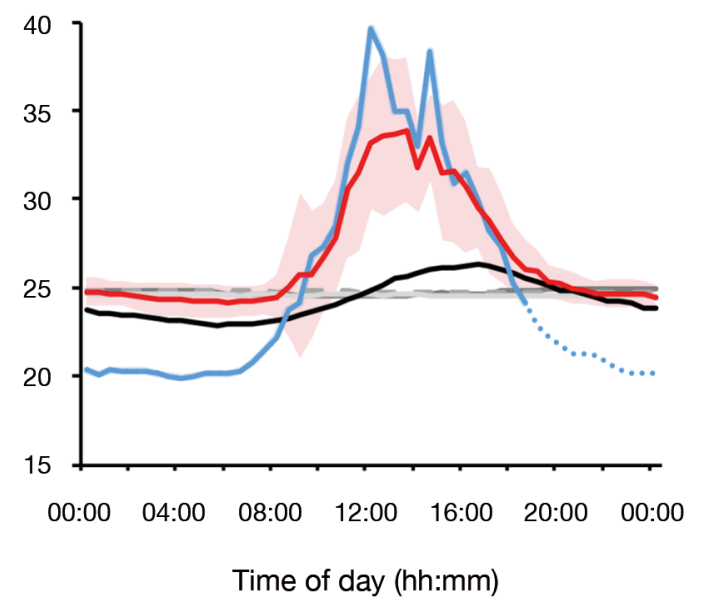

Time of day (hh:mm)

— Tortoise, $\longrightarrow$ Surface, $\longrightarrow$ Burrow $10 \mathrm{~cm},=$ Burrow $60 \mathrm{~cm},==-$ Burrow $110 \mathrm{~cm}, \longrightarrow$ Burrow $160 \mathrm{~cm}$

Fig. 3. Mean shell and environmental temperatures for 16 laboratory-reared yearling gopher tortoises approximately 1 mo following hard release in a longleaf pine forest in southwest Georgia, USA. Data are for (a) 9 yearlings, observed on 1 of 2 cool days (30 September and 3 October 2014), and (b) 7 other yearlings, observed on 1 of 2 warm days (1-2 October 2014). Shading represents $\pm 1 \mathrm{SD}$ of mean tortoise shell temperatures. (Environmental temperature errors are not shown.) Surface operative temperatures were not recorded during early night hours on warm days; for these instances, we present air temperatures $1.5 \mathrm{~m}$ above the ground (dotted blue line in b), collected by a weather station at the site

rammed the dowel with its gular protrusion and continued to do so as the dowel was slowly pulled out of the burrow, allowing us to grab the individual. In July 2016, we successfully used the same technique to capture another tortoise that had been hard-released nearly 2 yr earlier. In all 3 instances, the juveniles appeared highly motivated to expel the coaxial cable or dowel rod from their burrows, as documented for wild hatchling and juvenile gopher tortoises (Radzio et al. 2016). 


\subsection{Antipredator flight response and hiding time}

Tortoises on burrow aprons always hid in response to simulated predator approach ( $\mathrm{n}=41$ approaches on 23 individuals). This included 2 tortoises facing into burrows with their heads fully belowground when approached. In most instances, flight movements into burrows were rapid, and if tortoises were facing away from burrow entrances, they generally backed into the burrow rather than first turning around to face the entrance before entering. Mean FID was $34.1 \pm 14.5 \mathrm{~m}(2.3-58.5 \mathrm{~m}, \mathrm{n}=20)$ and did not differ from the estimated FID of wild 12 mo old gopher tortoises $(31.5 \mathrm{~m}$; Radzio \& O'Connor 2017) $\left(t_{19}=0.791, \mathrm{p}=0.439,1\right.$-sample $t$-test; Table 1$)$. When all observations were considered, hiding times of released tortoises $($ mean $=34.9 \pm 76.7 \mathrm{~min}, 1.8-360+\mathrm{min}$ ) did not differ from those of small wild juveniles $($ mean $=18.3 \pm 11.7 \mathrm{~min}, 3.4-50.0 \mathrm{~min}, \mathrm{n}=20$; Radzio \& O'Connor 2017) (Mann-Whitney $U_{41}=162.0, \mathrm{p}=$ 0.098). However, when we excluded 2 very long hiding time observations, where released yearlings did not emerge from burrows before cameras stopped recording ( 2 and $6 \mathrm{~h}$ later), hiding times of released individuals were slightly shorter (mean $=15.4 \pm$ $20.6 \min , 1.8-69.5 \mathrm{~min}, \mathrm{n}=21, U_{39}=122.0, \mathrm{p}=0.022$; Table 1). Although tortoises always hid during planned simulated predator approaches, we observed 4 instances outside simulated approaches where individuals sitting on burrow aprons did not retreat belowground or exhibited delayed response to our presence.

\subsection{Growth and survivorship}

Tortoises released on 1 September 2014 exhibited little change in MPL $(0.3 \pm 0.7 \mathrm{~mm},-0.9-1.4 \mathrm{~mm})$ or mass $(-0.1 \pm 3.1 \mathrm{~g},-4.3-4.9 \mathrm{~g}, \mathrm{n}=18)$ when recaptured 1-2 mo later. Tortoises released on 1 or 22 September 2014 exhibited substantial increases in MPL $(17.1 \pm 3.0 \mathrm{~mm}, 12.1-21.2 \mathrm{~mm})$ and mass $(55.3 \pm 17.6 \mathrm{~g})$ when recaptured 19-20 mo later in early May 2016 ( $\mathrm{n}=11$; Table 2). Mean MPL growth of released tortoises $(17.1 \pm 3.0 \mathrm{~mm})$ was lower than the predicted growth of wild tortoises $\left(20.1 \mathrm{~mm} \mathrm{yr}^{-1}, 95 \%\right.$ CI: $17.3-$ $23.1 \mathrm{~mm} \mathrm{yr}^{-1}$; Table 2$)$.

Nineteen of 30 (63\%) yearlings hard-released with radio transmitters on 1 September 2014 survived through at least 1 April 2015 (Fig. 4). Four others may have survived as long, but lost their transmitters in September-October and could not be located. Seven of 30 transmittered tortoises were either confirmed or suspected to have been depredated in fall 2014. Three were depredated by cottonmouths Agkistrodon piscivorus (radio transmitter signals emanating from the snakes); 1 by an unidentified animal (broken carcass); 2 apparently by red imported fire ants (intact carcass); and the seventh was not found, but its transmitter was recovered with bite marks in a nearby lowland area. At least 12 of $58(21 \%)$ yearlings released with (6 of 30) or without (6 of 28) transmitters in September 2014 survived $\geq 22$ mo, through 1 August 2016. These individuals represented 9 of 16 clutches. Generalized linear mixed model analysis indicated no relationship between location success on or after

Table 1. Flight initiation distances (FID) and hiding times of hard-released yearling and wild 0.5-4.0 yr old gopher tortoises in a longleaf pine forest in southwest Georgia, USA. Values are means $\pm \mathrm{SD}$

\begin{tabular}{|c|c|c|c|c|c|c|}
\hline \multirow[t]{2}{*}{ Category } & \multicolumn{2}{|c|}{$\longrightarrow$ FID $(\mathrm{m})$} & \multicolumn{2}{|c|}{$\begin{array}{l}\text { Hiding time }(\mathrm{min}) \\
\text { all observations }\end{array}$} & \multicolumn{2}{|c|}{$\begin{array}{l}\text { Hiding time (min) } \\
2 \text { outliers removed }\end{array}$} \\
\hline & Mean & $\mathrm{p}$ & Mean & $\mathrm{p}$ & Mean & $\mathrm{p}$ \\
\hline $\begin{array}{l}\text { Laboratory-reared, hard-released } \\
\text { Wild (Radzio \& O'Connor 2017) }\end{array}$ & $\begin{array}{c}34.1 \pm 14.5 \\
31.5\end{array}$ & $0.439^{\mathrm{a}}$ & $\begin{array}{l}34.9 \pm 76.7 \\
18.3 \pm 11.7\end{array}$ & $0.098^{b}$ & $\begin{array}{l}15.4 \pm 20.6 \\
18.3 \pm 11.7\end{array}$ & $0.022^{\mathrm{b}}$ \\
\hline
\end{tabular}

Table 2. Size at release in September 2014 and at final recapture in May 2016, growth, and predicted growth (based on observations of wild individuals) for 11 yearling gopher tortoises hard-released in a longleaf pine forest in southwest Georgia, USA. Values are means \pm SD. MPL: midline plastron length; na: not assessed

\begin{tabular}{|c|c|c|c|c|c|c|c|c|}
\hline \multirow{2}{*}{ Metric } & \multicolumn{2}{|c|}{ - September 2014} & \multicolumn{2}{|c|}{ May $2016-$} & \multicolumn{2}{|c|}{ Growth -} & \multicolumn{2}{|c|}{ Predicted growth } \\
\hline & Mean & Min-Max & Mean & Min-Max & Mean & Min-Max & Lower $95 \%$ CI & Upper $95 \%$ CI \\
\hline MPL (mm) & $65.3 \pm 3.2$ & $57.2-69.1$ & $82.4 \pm 4.0$ & $76.0-88.4$ & $17.1 \pm 3.0$ & $12.1-21.2$ & 17.3 & 23.1 \\
\hline Mass (q) & $86.8 \pm 9.0$ & $66.6-100.3$ & $142.1 \pm 17.4$ & $118.0-165.6$ & $55.3 \pm 17.6$ & $23.6-79.5$ & na & na \\
\hline
\end{tabular}




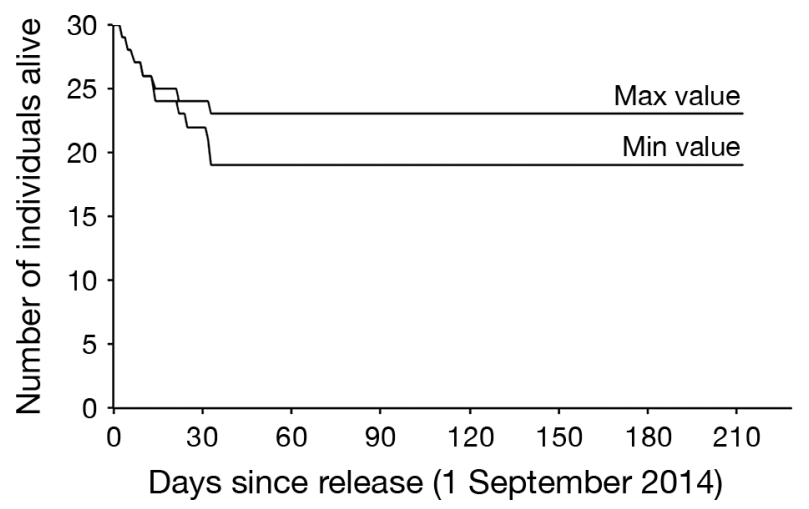

Fig. 4. Short-term survivorship of 30 laboratory-reared, yearling gopher tortoises hard-released with radio transmitters in a longleaf pine forest in southwest Georgia, USA, on 1 September 2014. Maximum survivorship reflects known mortalities. Minimum survivorship reflects known mortalities plus individuals that could not be located and were of unknown status

1 August 2016 and MPL at release in September 2014 $(\mathrm{p}=0.16)$.

Survivorship of 1 radio-transmittered yearling may have been improved by our field activities. On 1 October 2014, we located the yearling $20 \mathrm{~m}$ away from its inactive burrow and collected it to remove its radio transmitter and iButton and to measure growth. The iButton thermal profile indicated the juvenile had spent the previous 1-3 nights aboveground, atypical behavior compared to wild individuals. Instead of returning the juvenile to the point of capture, we placed it inside its burrow, which it continued using through at least 1 August 2016.

\section{DISCUSSION}

Despite having been raised indoors during their first year of life, yearling gopher tortoises generally exhibited natural attributes conducive to hard release and important for success in the wild. Within days of release, most radio-transmittered yearlings initiated burrows nearby and, like wild juveniles, showed a preference for burrowing under deadwood, fine-scale microhabitat selection that potentially reduces predation risk (Aresco 1999). Also consistent with wild individuals, most released yearlings spent the majority of their time in or near burrows but basked extensively on burrow aprons (Wilson et al. 1994, Pike \& Grosse 2006, Radzio 2017, Radzio \& O'Connor 2017). Basking raised body temperatures and, given strong thermal constraints on digestion in herbivorous ectotherms (Troyer 1987,
Zimmerman \& Tracy 1989, van Marken Lichtenbelt 1992, Tracy et al. 2005), likely plays an important role in the energetics and growth of juvenile gopher tortoises.

Wild hatchling and juvenile gopher tortoises manage predation risk associated with basking by limiting this activity primarily to burrow aprons and quickly hiding belowground in response to potential predators (Wilson et al. 1994, Radzio \& O'Connor 2017). Released tortoises always hid belowground during simulated predator approaches and exhibited long FIDs typical of wild individuals (Radzio \& O'Connor 2017). Notably, tortoises hid before having been observed by the approaching researcher, suggesting they used aerial or ground vibrations to detect the perceived threat (Radzio \& O'Connor 2017). The ability of released tortoises to use nonvisual cues to detect potential threats was particularly apparent in 2 approaches where individuals facing into burrows with their heads completely belowground also hid. Hiding times of released individuals were slightly shorter than reported for wild hatchlings and juveniles, when outlier observations were excluded, but this may have reflected lower burrow temperatures during this study (Radzio \& O'Connor 2017).

A potential limitation of our behavioral observations is that, primarily due to depredation occurring soon after release, we were unable to evaluate all radio-transmittered animals. Therefore, behavioral observations are biased toward individuals that successfully made the initial transition into the wild. However, observations included a large proportion of tortoises released with transmitters, and studied animals showed limited among-individual variation in activity or antipredator responses. Collectively, our findings indicate that laboratory-reared juvenile gopher tortoises exhibit largely natural behavior following hard release.

In addition to elevated predation risk, released animals can experience heightened environmental challenges and reduced physiological performance relative to wild individuals (Cook 1983, Field et al. 2007, Teixeira et al. 2007, Jarvie et al. 2015). Operative temperatures in direct sunlight exceeded lethal limits during much of the first full day following the first hard release. However, we did not document any mortality events during this period, suggesting yearlings avoided overheating by using shaded or subterranean microhabitats. Notably, tortoises exhibited little to no growth during the first 1-2 mo following release, possibly reflecting energetic state, adjustment to release, and the fact that tortoises in southwest Georgia grow little in September and October 
(Landers et al. 1982). Slow growth immediately following release may explain why individuals had grown slightly less than expected, based on observations of wild tortoises, when captured about $1.6 \mathrm{yr}$ later.

Minimum survivorship of hard-released yearlings documented here appears on par with that of younger, albeit larger, individuals soft-released in other investigations (Tuberville et al. 2015, Quinn et al. 2018). Tuberville et al. (2015) documented 0.35 minimum first-year survivorship and 0.88 minimum secondyear survival for gopher tortoises soft-released at 69 mo of age, and Wilson (1991) documented annual survival of about 0.45 for small wild juveniles (age = 1-4 yr). Based on these estimates, we would expect at least 9-18 of 58 hard-released individuals to be alive 2 yr later ([58 released animals $\times 0.35$ minimum first-year survivorship] $\times 0.88$ [or 0.45 ] second-year survival $=$ at least $9-18$ remaining individuals). Similarly, had we used first-year survivorship values for soft-released tortoises from Quinn et al. (2018; 0.46), we would expect at least 12-24 individuals to be alive 2 yr later. Correspondingly, at least 12 of 58 $(21 \%)$ of our hard-released tortoises were alive nearly 2 yr following release. Transmittered tortoises in our study also exhibited comparable survivorship through first winter dormancy (0.63-0.77) to that documented elsewhere for soft- and hard-released individuals (Quinn 2016, Quinn et al. 2018).

Although hard release may represent an effective release method for captive-reared juvenile gopher tortoises, between 5 and 7 of 30 (17-23\%) radiotransmittered yearlings were depredated before having constructed a long burrow. Thus, it is possible that we could have reduced initial mortality by implementing soft release measures, particularly providing starter burrows or excluding predators until individuals established fidelity to long burrows. However, juvenile gopher tortoise soft-releases also report substantial initial mortality (Holbrook et al. 2015, Tuberville et al. 2015, Quinn et al. 2018). Small pens can confine individuals or concentrate them along fence lines, potentially rendering young tortoises more vulnerable to predators such as fire ants and dogs (Holbrook et al. 2015, Tuberville et al. 2015, Quinn et al. 2018).

Similar to wild yearling gopher tortoises, few released yearlings likely reach maturity (Wilson 1991, Tuberville et al. 2015). Releasing juveniles at larger body sizes could increase recruitment into adult populations. Indeed, Tuberville et al. (2008) documented very high apparent survival for large translocated juvenile gopher tortoises beginning $1 \mathrm{yr}$ following release. Regardless of size effects on survivorship, establishing viable chelonian populations through release programs almost certainly requires long-term effort (Milinkovitch et al. 2013), but funding for conservation is often limited, short-term, and highly variable (Snyder et al. 1996). Recent work with Hermann's tortoises Testudo hermanni (Lepeigneul et al. 2014) and gopher tortoises (Quinn 2016, this study) indicates that hard release can provide an acceptable alternative to soft release in some situations. Availability of hard release as an option can render captive breeding and head-starting programs easier and less expensive to implement, which should promote continuity and increase odds of success.

The roles of various captivity programs in chelonian conservation require careful consideration, particularly with respect to other available options and the need to first address underlying causes of decline (Frazer 1992, Heppell et al. 1996, Spencer et al. 2017). Nevertheless, our findings indicate that some turtles are behaviorally resilient enough such that hatchlings can be studied in the laboratory and subsequently hard-released using minimal resources. Moreover, studies of released turtles can provide accurate information, including insights into habitat requirements, that can advance conservation efforts for imperiled species (Todd et al. 2016, Nafus et al. 2017). For example, we documented extensive, albeit highly secretive, basking by released yearling gopher tortoises, which points to the importance of maintaining and restoring warm, open longleaf pine habitats for this threatened species (Diemer 1986, Aresco \& Guyer 1999a,b, Radzio \& O'Connor 2017).

Acknowledgements. Maryann Fitzpatrick, Joe Midwig, Brent Mills, Wolfgang Nadler, and Jaclyn Smolinsky provided valuable assistance in the field and/or the laboratory. James Lee, Matt Hinderliter, and David Rostal shared important insights regarding hard release. Arthur Dunham, Susan Kilham, Willem Roosenburg, James Spotila, Kurt Buhlman, and an anonymous reviewer provided constructive comments for which we are very grateful. Additionally, we thank Paddy Wade, the Wade family, and the entire staff of Arcadia Plantation for granting access to their property and for ongoing support of research at the site. This work was supported with funding or materials by a McLean Fellowship in Ornithology and Environmental Science, Claudio Elia Memorial Fellowship in Environmental Science, the Wade Tract Research Endowment, Betz Chair Endowment in Environmental Science at Drexel University, the United States Army Construction Engineering Research Laboratory, and Tall Timbers Research Station and Land Conservancy. All work was conducted in accordance with approvals from the Drexel University Institutional Animal Care and Use Committee and a scientific collecting permit from the Georgia Department of Natural Resources. 


\section{LITERATURE CITED}

Aresco MJ (1999) Habitat structures associated with juvenile gopher tortoise burrows on pine plantations in Alabama. Chelonian Conserv Biol 3:507-509

Aresco MJ, Guyer CG (1998) Efficacy of using scute annuli to determine growth histories and age of Gopherus polyphemus in southern Alabama. Copeia 1998: 1094-1100

Aresco MJ, Guyer CG (1999a) Growth of the tortoise Gopherus polyphemus in slash pine plantations of southcentral Alabama. Herpetologica 55:499-506

Aresco MJ, Guyer CG (1999b) Burrow abandonment by gopher tortoises in slash pine plantations of the Conecuh National Forest. J Wildl Manag 63:26-35

Bates D, Maechler M, Bolker B, Walker S (2015) Fitting linear mixed-effects models using lme4. J Stat Softw 67 : $1-48$

Beck BB, Rapaport LG, Stanley Price MR, Wilson AC (1994) Reintroduction of captive-born animals. In: Olney PJS, Mace GM, Feistner ATC (eds) Creative conservation: interactive management of wild and captive animals. Springer, Dordrecht, p 265-286

Biggins E, Godbey JL, Hanebury LR, Luce B, Marinari PE, Matchett MR, Vargas A (1998) The effect of rearing methods on survival of reintroduced black-footed ferrets. J Wildl Manag 62:643-653

Böhm M, Collen B, Baillie JEM, Bowles P and others (2013) The conservation status of the world's reptiles. Biol Conserv 157:372-385

Buhlmann KA, Akre TSB, Iverson JB, Karapatakis D and others (2009) A global analysis of tortoise and freshwater turtle distributions with identification of priority conservation areas. Chelonian Conserv Biol 8:116-149

Butler JA, Bowman RD, Hull TW, Sowell S (1995) Movements and home range of hatchling and yearling gopher tortoises, Gopherus polyphemus. Chelonian Conserv Biol 1:173-180

Cagle FR (1939) A system of marking turtles for future identification. Copeia 1939:170-173

Congdon JD, Gibbons JW (1990) The evolution of turtle life histories. In: Gibbons JW (ed) Life history and ecology of the slider turtle. Smithsonian Institution Press, Washington, DC, p 45-54

Cook JC (1983) Rehabilitation of the desert tortoise (Gopherus agassizii). MSc thesis, California State Polytechnic University, Pomona, CA

* Crone EE, Pickering D, Schultz CB (2007) Can captive rearing promote recovery of endangered butterflies? An assessment in the face of uncertainty. Biol Conserv 139: 103-112

Diemer JE (1986) The ecology and management of the gopher tortoise in the southeastern United States. Herpetologica 42:125-133

Dodd CK Jr, Seigel RA (1991) Relocation, repatriation, and translocation of amphibians and reptiles: Are they conservation strategies that work? Herpetologica 47: 336-350

Douglass JF, Layne JN (1978) Activity and thermoregulation of the gopher tortoise (Gopherus polyphemus) in southern Florida. Herpetologica 34:359-374

Field KJ, Tracy CR, Medica PA, Marlow RW, Corn PS (2007) Return to the wild: translocation as a tool in conservation of the desert tortoise (Gopherus agassizii). Biol Conserv 136:232-245
Frazer NB (1992) Sea turtle conservation and halfway technology. Conserv Biol 6:179-184

Griffiths RA, Pavajeau L (2008) Captive breeding, reintroduction, and the conservation of amphibians. Conserv Biol 22:852-861

Harris BB (2014) Ecology of juvenile gopher tortoises (Gopherus polyphemus) on a Georgia barrier island. MSc thesis, University of Georgia, Athens, GA

*Heppell SS, Crowder LB, Crouse DT (1996) Models to evaluate headstarting as a management tool for long-lived turtles. Ecol Appl 6:556-565

Holbrook AL, Jawor JM, Hinderliter M, Lee JR (2015) A hatchling gopher tortoise (Gopherus polyphemus) care protocol for experimental research and head-starting programs. Herpetol Rev 46:538-543

IBM Corp. (2015) IBM SPSS statistics for Mac, Version 24.0. IBM Corp. Armonk, NY. www.ibm.com/analytics/ spss-statistics-software

Jarvie S, Senior AM, Adolph SC, Seddon PJ, Cree A (2015) Captive rearing affects growth but not survival in translocated juvenile tuatara. J Zool (Lond) 297:184-193

Landers JL, Garner JA, McRae WA (1980) Reproduction of gopher tortoises (Gopherus polyphemus) in southwestern Georgia. Herpetologica 36:353-361

Landers JL, McRae WA, Garner JA (1982) Growth and maturity of the gopher tortoise in southwestern Georgia. Bull Fla State Mus Biol Sci 27:81-110

Lepeigneul O, Ballouard JM, Bonnet X, Beck E and others (2014) Immediate response to translocation without acclimation from captivity to the wild in Hermann's tortoise. Eur J Wildl Res 60:897-907

*Lovich JE, Ennen JR, Agha M, Gibbons JW (2018) Where have all the turtles gone, and why does it matter? Bioscience 68:771-781

*Mansfield KL, Wyneken J, Porter WP, Luo J (2014) First satellite tracks of neonate sea turtles redefine the 'lost years' oceanic niche. Proc R Soc B 281:20133039

MATLAB (2018) MATLAB and statistics toolbox, release 2018b. The Mathworks, Inc., Natick, MA. www.mathworks.com

*McCoy ED, Mushinsky HR, Lindzey JK (2006) Population declines of the gopher tortoise on protected lands. Biol Conserv 128:120-127

*Milinkovitch MC, Kanitz R, Tiedemann R, Tapia W and others (2013) Recovery of a nearly extinct Galápagos tortoise despite minimal genetic variation. Evol Appl 6: 377-383

Moseby KE, Read JL, Paton DC, Copley P, Hill BM, Crisp HA (2011) Predation determines the outcome of 10 reintroduction attempts in arid South Australia. Biol Conserv 144:2863-2872

*Nafus MG, Esque TC, Averill-Murray RC, Nussear KE, Swaisgood RR (2017) Habitat drives dispersal and survival of translocated juvenile desert tortoises. J Appl Ecol 54:430-438

Nagy KA, Hillard S, Dickson S, Morafka DJ (2015) Effects of artificial rain on survivorship, body condition, and growth of head-started desert tortoises (Gopherus agassizii) released to the open desert. Herpetol Conserv Biol 10: 535-549

*Pedrono M, Sarovy A (2000) Trial release of the world's rarest tortoise Geochelone yniphora in Madagascar. Biol Conserv 95:333-342

Pike DA, Grosse A (2006) Daily activity of immature gopher tortoises (Gopherus polyphemus) with notes on commensal species. Fla Sci 69:92-98 
Platt WJ, Evans GW, Rathbun SL (1988) The population dynamics of a long-lived conifer (Pinus palustris). Am Nat 131:491-525

Quinn DP (2016) Head-starting as a conservation tool for gopher tortoises (Gopherus polyphemus). MSc thesis, University of Georgia, Athens, GA

Quinn DP, Buhlmann KA, Jensen JB, Norton TM, Tuberville TD (2018) First year post-release movement and survivorship of head-started gopher tortoises. J Wildl Manag 82:1545-1554

R Core Team (2018) R: a language and environment for statistical computing. R Foundation for Statistical Computing, Vienna

Radzio TA (2017) Physiological and behavioral ecology of juvenile gopher tortoises. PhD dissertation, Drexel University, Philadelphia, PA

Radzio TA, O'Connor MP (2017) Behavior and temperature modulate a thermoregulation-predation risk trade-off in juvenile gopher tortoises. Ethology 123:957-965

Radzio TA, Cox JA, Spotila JR, O'Connor MP (2016) Aggression, combat, and apparent burrow competition in hatchling and juvenile gopher tortoises (Gopherus polyphemus). Chelonian Conserv Biol 15:231-237

Radzio TA, Cox JA, O'Connor MP (2017) Hatching success and other reproductive attributes of gopher tortoises in southwest Georgia. Chelonian Conserv Biol 16:103-105

Reading RP, Miller B, Shepherdson D (2013) The value of enrichment to reintroduction success. Zoo Biol 32: 332-341

Smith LL, Tuberville TD, Seigel RA (2006) Workshop on the ecology, status, and management of the gopher tortoise (Gopherus polyphemus), Joseph W. Jones Ecological Research Center, 16-17 January 2003: final results and recommendations. Chelonian Conserv Biol 5:326-330

Snyder NFR, Derrickson SR, Beissinger SR, Wiley JW, Smith TB, Toone WD, Miller B (1996) Limitations of captive breeding in endangered species recovery. Conserv Biol 10:338-348

Spencer RJ, Van Dyke JU, Thompson MB (2017) Critically evaluating best management practices for preventing freshwater turtle extinctions. Conserv Biol 31:1340-1349

Stamps JA, Swaisgood RR (2007) Someplace like home: experience, habitat selection and conservation biology. Appl Anim Behav Sci 102:392-409

Swimmer Y, Arauz R, Higgins B, McNaughton L, McCracken M, Ballestero J, Brill R (2005) Food color and marine turtle feeding behavior: Can blue bait reduce turtle bycatch in commercial fisheries? Mar Ecol Prog Ser 295: 273-278

Teixeira CP, de Azevedo CS, Mendl M, Cipreste CF, Young RJ (2007) Revisiting translocation and reintroduction programmes: the importance of considering stress. Anim Behav 73:1-17

Todd BD, Halstead BJ, Chiquoine LP, Peaden JM, Buhlmann KA, Tuberville TD, Nafus MG (2016) Habitat selection by juvenile Mojave Desert tortoises. J Wildl Manag 80:720-728

Tracy CR, Flack KM, Zimmerman LC, Espinoza RE, Tracy CR (2005) Herbivory imposes constraints on voluntary hypothermia in lizards. Copeia 2005:12-19

* Troyer K (1987) Small differences in daytime body temperature affect digestion of natural food in a herbivorous lizard (Iguana iguana). Comp Biochem Physiol Part A Physiol 87:623-626

Tuberville TD, Norton TM, Todd BD, Spratt JS (2008) Longterm apparent survival of translocated gopher tortoises: a comparison of newly released and previously established animals. Biol Conserv 141:2690-2697

Tuberville TD, Todd BD, Hermann SM, Michener WK, Guyer C (2014) Survival, demography, and growth of gopher tortoises (Gopherus polyphemus) from three study sites with different management histories. J Wildl Manag 78: 1151-1160

Tuberville TD, Norton TM, Buhlmann KA, Greco V (2015) Head-starting as a management component for gopher tortoises (Gopherus polyphemus). Herpetol Conserv Biol 10:455-471

USFWS (US Fish and Wildlife Service), Alabama Department of Conservation and Natural Resources, Georgia Department of Natural Resources, Florida Fish and Wildlife Conservation Commission, Louisiana Department of Wildlife and Fisheries, Mississippi Department of Wildlife, Fisheries and Parks, South Carolina Department of Natural Resources (2013) Range-wide conservation strategy for the gopher tortoise (Gopherus polyphemus). USFWS, Atlanta, GA

*van Marken Lichtenbelt WD (1992) Digestion in an ectothermic herbivore, the green iguana (Iguana iguana): effect of food composition and body temperature. Physiol Zool 65:649-673

*Wilson DS (1991) Estimates of survival for juvenile gopher tortoises, Gopherus polyphemus. J Herpetol 25:376-379

Wilson DS, Mushinsky H, McCoy ED (1994) Home range, activity, and burrow use of juvenile gopher tortoises (Gopherus polyphemus) in central Florida. In: Bury RB, Germano DJ (eds) Biology of North American tortoises. Fish and Wildlife Research Report 13. US Department of the Interior, National Biological Survey, Washington, DC, p 147-160

Zimmerman LC, Tracy CR (1989) Interactions between the environment and ectothermy and herbivory in reptiles. Physiol Zool 62:374-409 
Appendix. Relationship between wild gopher tortoise length and age

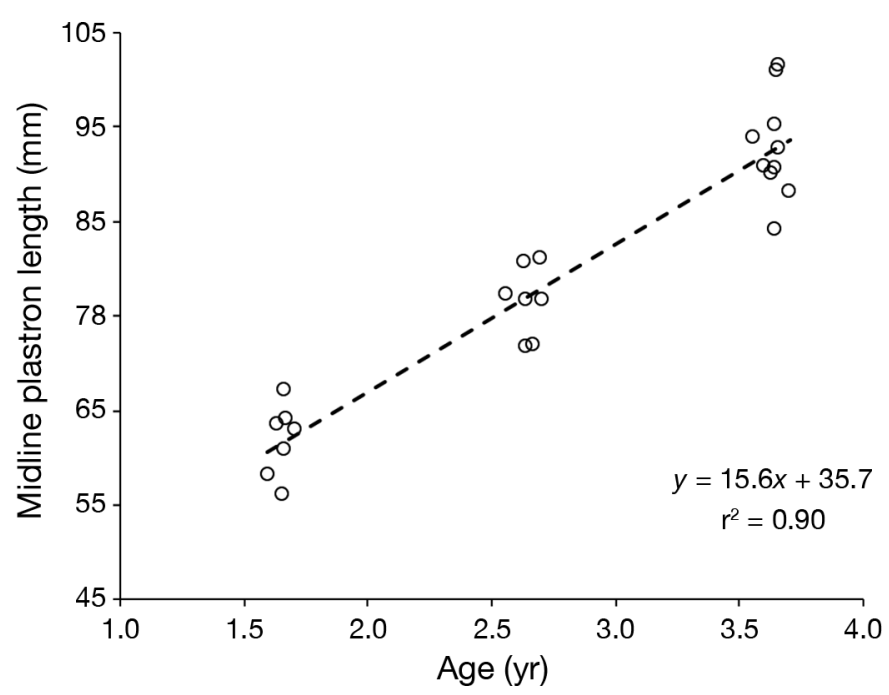

Fig. A1. Relationship between midline plastron length (MPL) and age for young wild juvenile gopher tortoises in a longleaf pine forest in southwest Georgia, USA. Each data point represents a unique individual ( $\mathrm{n}=24)$ captured in April-May of 2013, 2016, or 2019. Ages were determined by reading plastral scute rings (Aresco \& Guyer 1998), with the assumption that individuals hatched on 15 September (Landers et al. 1980, Radzio et al. 2017). The slope of the linear least squares regression (dashed line) indicates a growth rate of $15.6 \mathrm{~mm} \mathrm{yr}^{-1}$ (95\% CI: 13.4-17.9 mm yr-1)

Editorial responsibility: Michael Mahony,

Callaghan, New South Wales, Australia
Submitted: October 29, 2018; Accepted: July 24, 2019

Proofs received from author(s): September 15, 2019 